\title{
Breast Cancer during Pregnancy: An Interdisciplinary Approach in Our Institution
}

\author{
Cristina Pirvulescu ${ }^{\mathrm{a}} \quad$ Christine Mau $^{\mathrm{a}}$ Holger Schultz $^{\mathrm{a}}$ Antje Sperfeld ${ }^{\mathrm{a}}$ \\ Annette Isbruch $^{\mathrm{a}}$ Heike Renner-Lützkendorf ${ }^{\mathrm{a}}$ Sybille Loibl $^{\mathrm{b}} \quad$ Ulrike Freitag ${ }^{\mathrm{c}}$ \\ Gabriele Klühs $^{\mathrm{d}}$ Barbara Fleige $^{\mathrm{e}}$ Michael Untch $^{\mathrm{a}}$ \\ aDepartment of Gynecology and Obstetrics, Helios Hospital Berlin-Buch, ${ }^{b}$ German Breast Group, Neu-lsenburg,

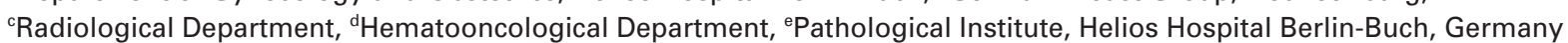

\section{Keywords}

Pregnancy-associated breast cancer - Outcome of pregnancy · Neoadjuvant chemotherapy .

Interdisciplinary care

\section{Summary}

Background: Breast cancer is the most common cancer diagnosed during pregnancy. Case Report: We report on a case of a 26-year-old woman who was diagnosed with right-sided breast cancer in her 15th week of gestation. We discussed possible treatment scenarios and the patient opted for neoadjuvant therapy with taxanes and anthracyclines during pregnancy, followed by delivery and then followed by surgery, antibody therapy, and radiotherapy. The patient received neoadjuvant chemotherapy with paclitaxel $80 \mathrm{mg} / \mathrm{m}^{2}$ weekly for 12 cycles, followed by 4 cycles of epirubicin and cyclophosphamide $\left(90 / 600 \mathrm{mg} / \mathrm{m}^{2}\right)$ every 3 weeks. Complete clinical response was seen after preoperative chemotherapy. After delivery of a healthy child at 40 weeks of gestation, she received breast-conserving surgery and axillary dissection. Anti-HER2 antibody treatment with trastuzumab was started concomitantly with adjuvant radiotherapy. Endocrine treatment with a gonadotropin-releasing hormone $(\mathrm{GnRH})$ analog and tamoxifen for 5 years was planned to be started after radiotherapy. Conclusion: Treatment of breast cancer during pregnancy requires an interdisciplinary approach and careful consideration of the patient's stage of disease, the gestational age, and the preferences of the patient and her family.

\author{
Schlüsselwörter \\ Mammakarzinom in der Schwangerschaft . \\ Schwangerschaftsoutcome · Neoadjuvante \\ Chemotherapie $\cdot$ Interdisziplinäre Betreuung
}

\section{Zusammenfassung}

Hintergrund: Das Mammakarzinom ist das am häufigsten diagnostizierte Malignom während der Schwangerschaft. Fallbericht: Wir berichten über den Fall einer 26-jährigen Frau, bei der ein rechtsseitiges Mammakarzinom in der 15. Schwangerschaftswoche diagnostiziert wurde. Mögliche Behandlungsstrategien wurden mit der Patientin und ihren Angehörigen diskutiert. Sie entschied sich für die neoadjuvante Chemotherapie mit Taxanen und Anthrazyklinen während der Schwangerschaft, gefolgt von der Entbindung und anschließender operativer Therapie sowie Antikörpertherapie und Bestrahlung. Die Patientin erhielt neoadjuvant Paclitaxel ( $80 \mathrm{mg} / \mathrm{m}^{2}$ ) wöchentlich über 12 Zyklen, gefolgt von $4 \mathrm{Zy-}$ klen Epirubicin und Cyclophosphamid $\left(90 / 600 \mathrm{mg} / \mathrm{m}^{2}\right.$ ) alle 3 Wochen. Ein komplettes klinisches und sonographisches Ansprechen wurde im weiteren Verlauf nachgewiesen. Nach der Geburt eines gesunden Kindes in der 40. Schwangerschaftswoche erhielt die Patientin eine brusterhaltende Therapie und axilläre Lymphonodektomie. Eine Anti-HER2-Antikörperbehandlung mit Trastuzumab wurde zusammen mit der adjuvanten Bestrahlung begonnen. Eine Hormonbehandlung mit einem Gonadotropin-Releasing-Hormon ( $\mathrm{GnRH}$ )-Analogon und Tamoxifen für 5 Jahre wurde mit der Patientin geplant. Schlussfolgerung: Die Behandlung des Mammakarzinoms in der Schwangerschaft setzt eine interdisziplinäre Betreuung unter Berücksichtigung des Krankheitsstatus, des Schwangerschaftsalters und der Erwartungen der Patientin und ihrer Familie voraus.

\section{KARGER \\ Fax +497614520714 \\ Information@Karger.de}

www.karger.com (c) 2012 S. Karger GmbH, Freiburg

1661-3791/12/0074-0311\$38.00/0

Accessible online at:

www.karger.com/brc
Cristina Pirvulescu, MD

Department of Gynecology and Obstetrics

Helios Hospital Berlin-Buch

Schwanebecker Chaussee 50, 13125 Berlin, Germany

Tel. +49 309401 533-09, Fax -00

cristina.pirvulescu@helios-kliniken.de 


\section{Introduction}

Pregnancy-associated breast cancer (PABC) is a rare disease with an incidence of 1:3000, generally defined as cancer that occurs during pregnancy or within 1 year after delivery. The pathological features of breast cancer diagnosed during pregnancy have been analyzed in numerous studies. Because of the retrospective nature of such studies and the paucity of case-control studies, it is impossible to directly compare the biological properties of breast cancer in pregnant and nonpregnant patients of similar age [1].

Treatment options are limited when the disease is diagnosed during pregnancy. Breast surgery can be safely performed during all trimesters of pregnancy, with minimal risk to the developing fetus. It may be chosen to wait until the 12 th week of gestation has been completed, because of a higher risk of spontaneous abortion [2]. During surgery, monitoring of the fetus should take place depending on gestational age. Sentinel lymph node biopsy has not been systematically evaluated in PABC patients. The dose of radiation to the fetus through the use of technetium has been estimated to be low, and some reports have shown that pregnant patients could be offered sentinel lymph node biopsy after counseling with regard to the amounts of radiation involved, calculated to reach a maximum of $4.3 \mathrm{mGy}$. Isosulfan blue dye mapping is not recommended in pregnant patients because of possible side effects, i.e. anaphylaxis [3].

The indications for adjuvant chemotherapy in pregnant patients are identical to those in non-pregnant patients. However, adjuvant hormonal therapy, monoclonal antibody treatment (trastuzumab) and radiation therapy cannot be given during pregnancy because of possible complications, fetal toxicities and late sequelae [2].

Placental transfer of trastuzumab has been observed in animal studies. Several case reports have described reversible oligo- or anhydramnions as a result of exposure to trastuzumab during pregnancy [3]. Neonatal defects from tamoxifen have been described in the genital tract in female mice. Although tamoxifen has safely been given in patients with metastatic breast cancer without damage to the child, there are other reports of birth defects such as Goldenhar syndrome and ambiguous genitalia in children born to women exposed to tamoxifen [4]. Radiation exposure in the 1st trimester of gestation has been associated with an increased risk of mental retardation and fetal malformation. Radiotherapy is usually planned after chemotherapy and surgery have been completed. Therefore the initiation of hormonal and radiation therapy can be postponed without compromising efficacy.

Preoperative neoadjuvant chemotherapy may be indicated for the therapy of locally advanced breast cancer according to recent consensus guidelines $[2,3,5]$.

The optimal timing of chemotherapy is crucial. While it is obviously preferable to postpone chemotherapy until after delivery, this is not always possible. Locally advanced breast cancer needs to be treated in a preoperative concept. In addition, for patients whose tumors do not express estrogen and/ or progesterone receptors, a late start of chemotherapy, i.e. later than 3 weeks after surgery, may worsen the prognosis as compared to an early start of chemotherapy [6].

The efficacy of very late adjuvant chemotherapies, e.g. starting later than 8 weeks after surgery, is unknown. Thus, chemotherapy may need to be started during pregnancy. Chemotherapy is contraindicated in the 1st trimester of pregnancy when the fetus undergoes organogenesis and is vulnerable to the teratogenic effects of chemotherapeutic substances [7]. If chemotherapy cannot be postponed to the 2nd trimester of pregnancy, abortion might be an option. Abortion by itself has never been proven to have a beneficial therapeutic effect in breast cancer [8]. In the 2nd and 3rd trimesters, chemotherapy is relatively safe as illustrated by the most recent series of patients reported by investigators from the M.D. Anderson Cancer Center and from the Royal Marsden Hospital [9, 10].

Antiemetics such as short-term glucocorticosteroids and most serotonin receptor III antagonists are considered safe in pregnancy. Ondansetron has the longest safety record, and no increased frequency of adverse effects has been reported in connection with treating pregnant patients [4].

\section{Case Report}

Our patient, a 26-year-old Caucasian, gravida 1, para 0 , was diagnosed June 2009 with invasive ductal cancer of the right breast in the 15 th week of gestation. The patient wished explicitly to continue the pregnancy and also to have optimal therapy against her breast cancer. The family history was negative concerning breast cancer. She declined a chest X-ray with abdominal shielding and a screening noncontrast magnetic resonance imaging (MRI) of the thoracic and lumbar spine.

We evaluated all staging (abdominal ultrasound) and histopathological results in our interdisciplinary tumor board and recommended, in the 15 th week of gestation, neoadjuvant chemotherapy with paclitaxel weekly for 12 cycles, followed by 4 applications of epirubicin and cyclophosphamide every 3 weeks (table 1 ). In addition, we discussed with the patient the potential efficacy and safety of a sentinel lymph node biopsy before chemotherapy, given that the sensitivity of sentinel lymph node mapping is reduced when only 1 modality is used (contraindication for isosulfan blue dye mapping because of anaphylaxis). She finally decided against sentinel node biopsy. After delivery, we recommended surgery (breastconserving approach depending on tumor response after neoadjuvant chemotherapy and primary axillary lymph node dissection), and after puerperium (approx. 2 weeks after delivery), adjuvant radiotherapy, antiHER2 therapy with trastuzumab and anti-endocrine therapy.

We discussed intensively with the patient and her family the therapeutic options and outcome of pregnancy during this treatment. The patient was under continuous additional care of our breast nurse and psychooncologist. The departments of hematooncology, obstetrics, embryology, neonatology, toxicology, and radiology were involved.

Neoadjuvant chemotherapy was initiated in July 2009 (19th gestational week) after subcutaneous implantation of a port system. The patient received paclitaxel weekly $80 \mathrm{mg} / \mathrm{m}^{2}$ given for 12 weeks, followed by 4 cycles of epirubicin $90 \mathrm{mg} / \mathrm{m}^{2}$ and cyclophosphamide $600 \mathrm{mg} / \mathrm{m}^{2}$ ), every 3 weeks. The tumor was marked with a titanium clip after 9 cycles 
Table 1. Tumor characteristics

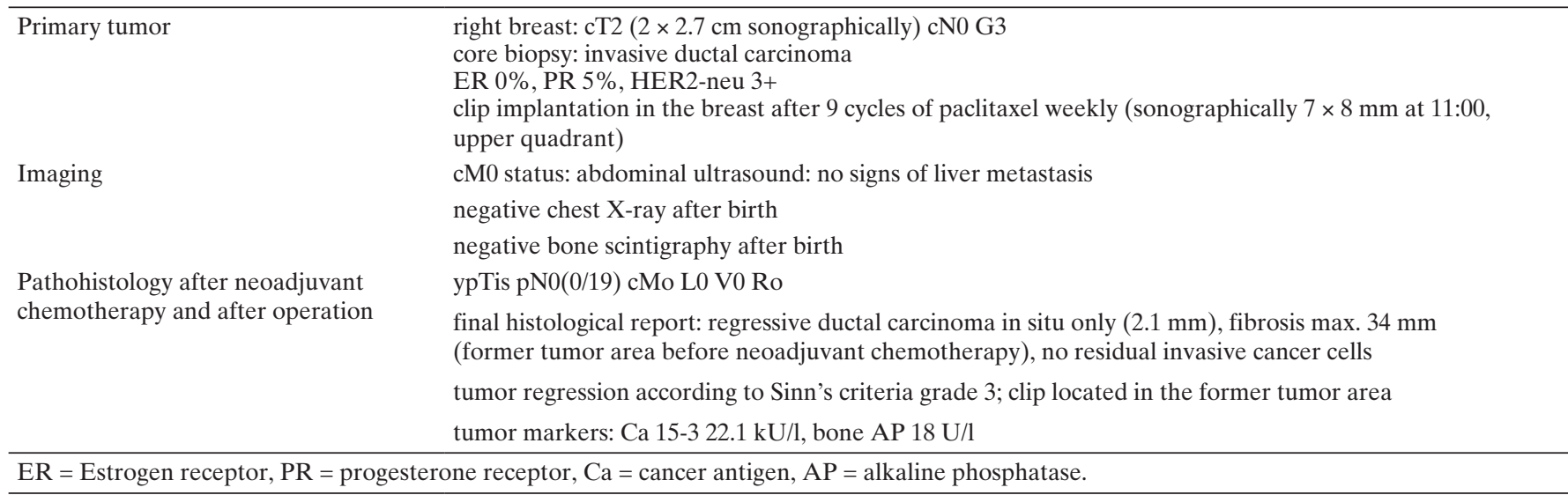
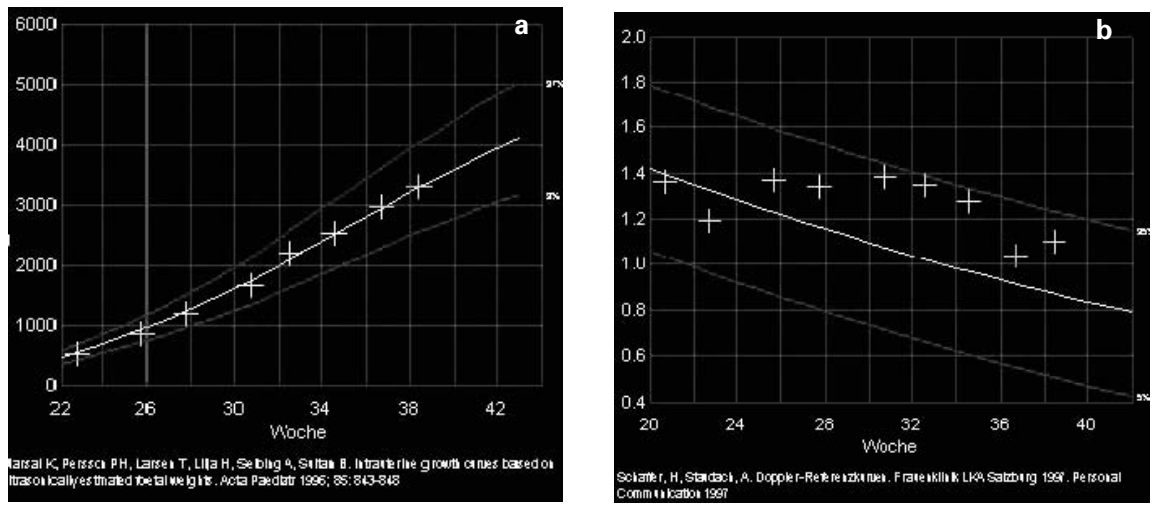

Fig. 1. Pregnancy characteristics. (a) Weight nomogram, (b) pulsatility index (PI) of the umbilical artery, (c) apical 4-chamber view at the 21th gestational week, (d) sagittal view of the fetus at the 21th gestational week.
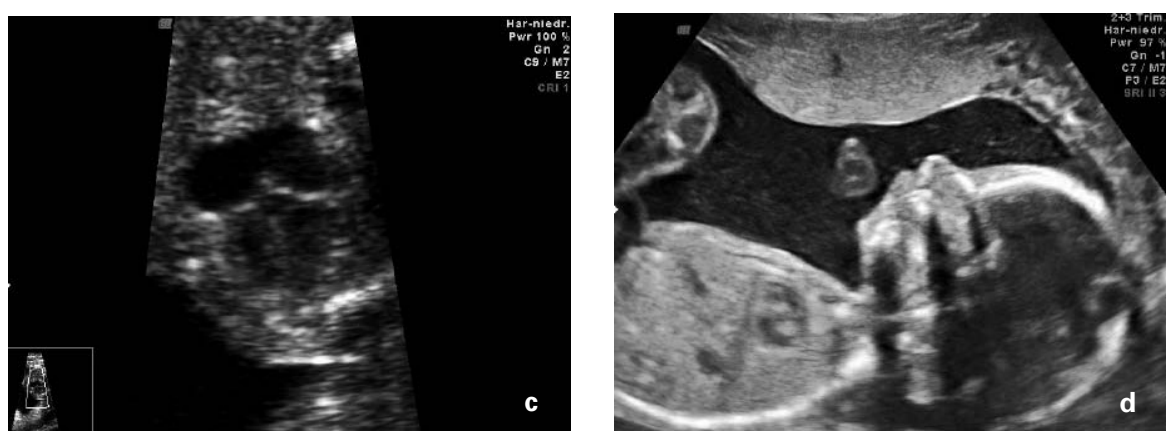

with paclitaxel. The chemotherapy was well tolerated; mainly hematological side effects (anemia, neutropenia) and alopecia occurred.

The pregnancy was closely monitored during the chemotherapy in our prenatal department. There were no signs of malformations or other suspicious signs of the fetus, the placenta and amniotic fluid in ultrasound screening or fetal cardiotocography (fig. 1a-d).

Delivery by induction of birth with dinoprostongel was performed in the 40th week of gestation. The spontaneous delivery was uncomplicated, with a healthy girl with no apparent malformations (3630 g, APGAR 9/10/10, $\mathrm{pH}$ 7.32). The patient decided against breast feeding.

At 2 weeks after delivery, she underwent right quadrantectomy plus axillary lymph node dissection. After puerperium, she received radiotherapy with boost and trastuzumab concomitant to radiotherapy every 3 weeks. The anti-HER 2 treatment was planned for 1 year. Because of positivity for the progesterone receptor we recommended additional anti-endocrine therapy with a gonadotropin-releasing hormone $(\mathrm{GnRH})$ analog and tamoxifen for 5 years. All pre- and postoperative staging in- vestigations showed no signs of metastases. No complications of the baby were reported.

The patient has been registered in the BCP (Breast Cancer in Pregnancy) study of the German Breast Group. She received anti-HER2 therapy until February 2011 and declined an additional endocrine treatment.

\section{Conclusions}

This is one of the first reports on an inverse sequence of paclitaxel followed by anthracycline during pregnancy. This has been chosen based on the data by Earl et al. [11], which demonstrated a significant increase in pathological complete response (pCR) by giving neoadjuvant sequential paclitaxel 
with or without gemcitabine, followed by epirubicin and cyclophosphamide. Data on taxanes during pregnancy are limited; however, a recent overview by Mir et al. [12] demonstrated no detrimental effects on the infant. In the treatment of the pregnant breast cancer patient, the evidence upon which we base our decisions has been largely limited to case reports, case-control studies, and retrospective cohorts. There is no 'hard' indication to terminate the pregnancy since the maternal prognosis will not be influenced. Due to physiologic pregnancy-related changes in the breast, the interpretation of clinical findings, breast ultrasound and mammography is challenging. There is often a diagnostic delay in detecting PABC. In the 3rd trimester, breast-conserving surgery and radiotherapy after delivery represent an option. Chemotherapy can be administered relatively safe in the 2 nd and 3rd trimester. Radiotherapy, hormonal therapy and trastuzumab are contraindicated during pregnancy. Patients with PABC should be seen and treated in an interdisciplinary setting, preferably in a specialized center [13].

It is important to emphasize the role of cancer registries in the improvement of care for PABC patients. In April 2003, the German Breast Group launched a prospective and retrospective registry for women with breast cancer during pre- gnancy. Until March 2011, 400 patients with the diagnosis of breast cancer during pregnancy were prospectively and retrospectively collected [14]. All women with a diagnosis of breast cancer during pregnancy can be registered independently of the applied therapy. The primary end point of the registry is the outcome of the baby 4 weeks after delivery. Secondary end points are the outcome of the mother, complications during pregnancy, the outcome of the child after 5 years, the biological and histological properties of the cancer, tumor stage at the time of diagnosis, the therapies used, and the methods used during pregnancy to diagnose cancer. Randomized controlled studies are unlikely to succeed because of the rare incidence of PABC. Nevertheless, it is crucial to enable the collection of prospective or retrospective data such as those collected in the database of the German Breast Group, for the improvement of interdisciplinary management of PABC.

\section{Disclosure Statement}

The authors declare no conflicts of interest.

\section{References}

1 Woo JC, Yu T, Hurd TC: Breast cancer in pregnancy: a literature review. Arch Surg 2003;138:91-98.

2 Arbeitsgemeinschaft Gynäkologische Onkologie e.V. (AGO): www.ago-online.de/.

$>3$ Loibl S, von Minckwitz G, Gwyn K: Breast carcinoma during pregnancy. International recommendations from an expert meeting. Cancer 2006; 106:237-246.

4 Loibl S: New therapeutic options for breast cancer during pregnancy. Breast Care 2008;3:171-176.

$\checkmark 5$ Kaufmann M, Hortobagyi GN, Goldhirsch A, Scholl S, Makris A, Valagussa P, Blohmer JU, Eiermann W, Jackesz R, Jonat W, Lebeau A, Loibl S, Miller W, Seeber S, Semiglazov V, Smith R, Souchon R, Stearns V, Untch M, von Minckwitz G: Recommendations from an international expert panel on the use of neoadjuvant (primary) systemic treatment of operable breast cancer: an update. J Clin Oncol 2006;24:1940-1949.

6 Colleoni M, Bonetti M, Coates AS, CastiglioneGertsch M, Gelber RD, Price K, Rudenstam CM, Lindtner J, Collins J, Thurlimann B, Holmberg S, Veronesi A, Marini G, Goldhirsch A: Early start of adjuvant chemotherapy may improve treatment outcome for premenopausal breast cancer patients with tumors not expressing estrogen receptors. The International Breast Cancer Study Group. J Clin Oncol 2000;18:584-590.

7 Cardonick E, Iacobucci A: Use of chemotherapy during human pregnancy. Lancet Oncol 2004;5: 283-291.

8 Barthelmes L, Davidson LA, Gaffney C, Gateley CA: Pregnancy and breast cancer. BMJ 2005;330:1375-1378.

$\checkmark 9$ Ring AE, Smith IE, Jones A, Shannon C, Galani E, Ellis PA: Chemotherapy for breast cancer during pregnancy: an 18-year experience from five London teaching hospitals. J Clin Oncol 2005;23:41924197.

10 Hahn KM, Johnson PH, Gordon N, Kuerer H, Middleton L, Ramirez M, Yang W, Perkins G, Hortobagyi GN, Theriault RL: Treatment of pregnant breast cancer patients and outcomes of children exposed to chemotherapy in utero. Cancer 2006;107:1219-1226.

11 Earl HM, Vallier A, Hiller L, Fenwick N, Ddawela M, Hughes-Davies L, Provenzano E, McAdam K, Hickish T, Caldas C: Neo-tAnGo: A neoadjuvant randomized phase III trial of epirubicin/cyclophosphamide and paclitaxel \pm gemcitabine in the treatment of women with high-risk early breast cancer (EBC): First report of the primary endpoint, pathological complete response (pCR). J Clin Oncol 2009;27(suppl):15s, abstr 522 .

12 Mir O, Berveiller P, Goffinet F, Treluyer JM, Serreau R, Goldwasser F, Rouzier R: Taxanes for breast cancer during pregnancy: a systematic review. Ann Oncol 2010;21:425-426.

13 Amant F, Deckers S, Van Calsteren K, Loibl S, Halaska M, Brepoels L, Beijnen J, Cardoso F, Gentilini O, Lagae L, Mir O, Neven P, Ottevanger N, Pans S, Peccatori F, Rouzier R, Senn HJ, Struikmans H, Christiaens MR, Cameron D, $\mathrm{Du}$ Bois A: Breast cancer in pregnancy: recommendations of an international consensus meeting. Eur J Cancer 2010;46:3158-3168.

14 Loibl S, Amant F, Kaufmann M, Ring A, Sileny $\mathrm{H}$, Giermek J, Fehm T, Bontenbal M, Heinrigs M, Lenhard M, Scherr I, Mehta K, von Minckwitz G: 313 patients with breast cancer during pregnancy - results from a prospective and retrospective registry (GBG-20/BIG02-03). Poster discussion, San Antonio Breast Cancer Symposium (SABCS) 2010. 